\title{
Metoclopramide-Induced Dystonic Reaction in an Infant
}

\author{
Songul Tomar-Guneysu' ${ }^{1,}$, Okşan Derinoz-Guleryuz ${ }^{1}$, \\ Ozlem Colak ${ }^{1}$, Ilknur Fidanci ${ }^{1}$
}

${ }^{1}$ Gazi University Faculty of Medicine, Department of Pediatrics, Division of Pediatric Emergency, Ankara, Turkey

\section{*Correspondence}

tomarsongul@gmail.com

(Songul Tomar Guneysu)

\begin{abstract}
Metoclopramide-induced dystonic reaction (MIDR) is a clinical condition that can be seen even in all age groups even in treatment doses. A nine-monthold girl was brought to our emergency department with acute dystonic reaction that occurred after her 2.5 -years-old sister gave her a $10 \mathrm{mg} / \mathrm{kg}$ metoclopramide tablet two hours before admission to the hospital. Diphenhydramine was given to the patient. One hour later, the patient's clinical findings regressed and patient was hospitalized, and was discharged from the hospital after 66 hours without sequelae. Although metoclopramide-induced dystonic reaction is frequently reported, the number of cases under one year of age is very limited. The case presented in this report is a patient who received a higher drug dose compared to other cases reported in the literature and recovered without sequelae after followup. The most important factor resulting in poisoning in children is not arranging the living spaces of the children by the parents. The easiest way to prevent such cases is to educate families on this issue.
\end{abstract}

\section{Keywords}

Child, Infant, Metoclopramide poisoning

\section{Introduction}

Metoclopramide-induced dystonic reaction (MIDR) is a clinical condition that can be seen even in all age groups even in treatment doses [1]. Although MIDR is frequently reported in the literature, the number of cases under one year of age is very low [2-4].

Unlike other cases in the literature, the case presented in this report was under one year of age and developed MIDR after accidental intake of metoclopramide, and recovered without sequelae after symptomatic follow-up.

\section{Case report}

A previously healthy nine-month-old girl presented with complaints of throwing her head back, looking at a fixed point, drowsiness and weakness after waking up about two hours before admission to the hospital. It was learned from her father that she was conscious during the incident. She was playing with her 2.5-year-old sister with medicine boxes of their grandmother containing metoclopramide about five hours before the incident. The family stated that metoclopramide 10,10-mg tablets (total dose taken: $10 \mathrm{mg} / \mathrm{kg}$ ) in total were missing. They realized the event after the complaints developed in the infant, and thought that the 2.5-year-old sister could have given these tablets to the infant. The older sister did not have any symptoms. In the initial evaluation, vital signs were within normal limits of her age. Modified Glasgow Coma Score was 14 , she was agitated, and showed little interest to her surroundings. Five hours after taking the drugs, tonus increase developed throughout the body, which was more prominent in the lower limbs and neck. On examination, it was observed that she had generalized myoclonic beats without any loss of consciousness. Light reflex was bilateral, pupils were isochoric, deep tendon reflexes were normal and there was no pathological reflex. No abnormalities were detected in laboratory tests (Complete blood count, blood sugar, serum electrolytes, blood gas, creatine kinase).

Gastric lavage and activated charcoal were not performed as a considerable amount of time had passed after drug intake and the patient was symptomatic. $1.25 \mathrm{mg} / \mathrm{kg} \mathrm{IV}$ diphenhydramine was given and symptoms disappeared dramatically in the first hour. Due to the possible side 
effects, she was hospitalized in the Intensive Care Unit and dystonia was not observed again. During admission, both children were followed up by the Social Pediatrics Department and the Child Protection Unit due to carelessness since the children were left alone with medications, and the patient was discharged after approximately 66 hours of follow-up. Forensic notification was made for the patient due to both carelessness and poisoning.

Written informed consent was obtained from the families of patients who participated in the study.

\section{Discussion}

Metoclopramide can develop an acute dystonic reaction (ADR) even at treatment doses [1, 5]. Patients present with contractions in the face, neck and back muscles, dysarthria, trismus opisthotonos, torticollis and oculogyric crisis [6]. It can be treated with pharmacological agents such as biperiden, diphenhydramine [1].

In a study, MIDR was found that $43.6 \%$ of 55 cases aged 5 - 204 months within a five-year period. It was also reported that $77.8 \%$ of the patients aged $0-72$ months who presented with dystonia developed dystonia after the side effects of the drugs given in treatment dose. No accidental intake was reported in this age group [7]. In this respect, our case was exposed to accidental drug intake by her older sister, and differs from other cases in the literature.

MIDR is very rarely seen in infants. In the literature, metoclopramide poisoning have been reported in two infant cases who were four and a half and six months old. In both cases, the patients were iatrogenically given excess drug doses by their families ( $2 \mathrm{mg} / \mathrm{kg}$ and $3 \mathrm{mg} / \mathrm{kg}$, respectively) and then developed ADR. Although it was symptomatic in both cases, it was not treated with any pharmacological agent $[3,4]$. Similar to the above mentioned two cases in the literature, our case is under one year of age; however, unlike these cases, the drug was not given iatrogenically, 10 $\mathrm{mg} / \mathrm{kg}$ metoclopramide was accidentally given by her older sister. In addition, contrary to the cases in the literature, diphenhydramine treatment was applied to our patient since our patient was symptomatic in the hospital admission.

As far as we know, this baby is the first case to receive the highest dose of metoclopramide in the age group and was discharged with full recovery.

In children, delibrate poisoning with drugs or chemicals can be observed. However, the probability of accidentally taking medications at high doses at a young age is very low [8]. One study was reported that dystonia developing as a result of the side effects of the drugs given in treatment dose was seen most frequently in children over the age of 12 , and the frequency was higher in the 13 - 18 age group compared to the $<12$ age group [7]. Our case was also a nine-month-old baby and she took the medicine while an adult was at home. In fact, it is not easy for an infant to open the box of medicines and remove medicines from the blister, and swallow $1010-\mathrm{mg}$ tablets. It is more likely that her older 2.5-year-old sister performed such actions. Nevertheless, it has been understood that children are not under the supervision of their parents. Parents should make sure their children are safe.

In conclusion, the case presented in this report was under one year of age, and received the highest dose of metoclopramide reported in the infant age group. The most important factor resulting in poisoning in children is that the living spaces for them are not regulated by the parents. The easiest way to prevent such cases is to educate families on this issue. For this purpose, more careful storage of medicines should be carried out at home and for the production of medicine boxes so that they cannot be opened easily. Parents should be more careful and concerned so that accidental drug poisoning can be reduced. In addition, since the adverse reactions of metoclopramide can be seen even in treatment doses, medication history should be questioned in every patient admitted to the emergency department with ADR and physical examination should be performed carefully for other neurological findings that may accompany.

\section{ACKNOWLEDGEMENTS}

We would like to acknowledge our ED staff for their support.

\section{CONFLICT OF INTEREST}

The authors declare no conflict of interest.

\section{AUTHOR CONTRIBUTIONS}

Songul Tomar-Guneysu and Oksan Derinoz-Guleryuz designed the study. Songul Tomar-Guneysu collected the data, Songul Tomar-Guneysu, Oksan Derinoz-Guleryuz, Ozlem Colak and Ilknur Fidanci analyzed the data, Songul Tomar-Guneysu and Oksan Derinoz-Guleryuz analyzed the results and drafted the manuscript, Songul Tomar-Guneysu manuscript preparation, final approval.

\section{REFERENCES}

[1] Cezard C, Nisse P, Quaranta S, Peucelle D, Mathiue-Noolf M. Acute dystonia from metoclopramide in children. Therapie. 2003;58:36770 .

[2] Low L. C.; Goel K. M. Metoclopramide poisoning in children. Arch Dis Child. 1980;55:310-311.

[3] Sahìn Bariş; Türkmen Mehmet Atìlla; Kavukçu Salìh. Iatrogenic metoclopramide toxicity in an infant presenting to a pediatric emergency department. Pediatr Emerg Care. 2001;17:150-151.

[4] Batts Ke1th F.; Munter David W. Metoclopramide toxicity in an infant. Pediatr Emerg Care. 1998;14:39-41.

[5] Hibbs Anna Maria; Lorch Scott A. Metoclopramide for the treatment of gastroesophageal reflux disease in infants: a systematic review. Pediatrics. 2006;118:746-752.

[6] Söğüt Ö., Kaya H., Solduk L., Dokuzoğlu M.A. Metoklopramid kullanımına bağlı gelişen akut distoni: iki olgu sunumu. Journal of Emergency Medicine Case Reports. 2011;2:50-53. (In Turkish)

[7] Derınoz Oksan; Caglar Ayla Akca. Drug-induced movement disorders in children at paediatric emergency department:'dystonia'. Emerg Med J. 2013;30:130-133. 
${ }^{[8]}$ Kara Bülent; Biçer Ümit; Gökalp Ayşe Sevim. Çocuk istismarı. J Paediatr Child H. 2004;47:140-151. ( In Turkish)
How to cite this article: Songul Tomar-Guneysu, Okşan DerinozGuleryuz, Ozlem Colak, Ilknur Fidanci. Metoclopramide-Induced Dystonic Reaction in an Infant. Signa Vitae. 2020;16(1):203-205. doi:10.22514/sv.2020.16.0029. 